\title{
Peter Angele, MD—Associate Editor
}

\author{
Jon Karlsson · Roland Becker
}

Published online: 2 October 2014

(C) European Society of Sports Traumatology, Knee Surgery, Arthroscopy (ESSKA) 2014

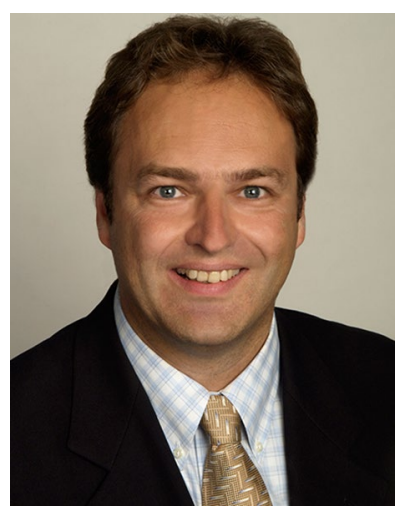

Peter Angele, MD, has been appointed an Associate Editor of the Knee Surgery Sports Traumatology and Arthroscopy Journal and will replace Mats Brittberg. At the same time, we would like to thank Mats Brittberg for his outstanding services to the journal.

Peter has served the journal both as a reviewer and an Editorial Board Member. He was trained at the University of Ulm in Germany, graduating in 1994.

His orthopaedic residency was spent at the sporthopaedicum straubing and in the Department of Trauma Surgery, University Hospital, Regensburg, Germany, under the leadership of Professor Dr. Michael Nerlich and became a board-certified specialist in Surgery (2001), in Trauma Surgery (2004) and in Orthopaedic Surgery (2006). From 2001

J. Karlsson $(\bowtie)$

Department of Orthopaedics, Sahlgrenska University Hospital, 43180 Mölndal, Sweden

e-mail: jon.karlsson@telia.com

R. Becker

Department of Orthopaedic and Traumatology, City Hospital Brandenburg, Hochstrasse 29, 14770 Brandenburg, Havel, Germany to 2008, he worked as a consultant at the Department of Trauma Surgery at the University Hospital, Regensburg.

He completed an 18-month Research Fellowship at Case Western Reserve University, Ohio, USA, under Prof. Goldberg and Prof. Brian Johnstone, PhD. In addition, he spent a 2-month Research Fellowship in the Department of Orthopaedic Surgery, Brigham and Women's Hospital, Boston, Massachusetts, under Prof. Myron Spector, PhD.

In April 2008, Peter has been appointed Head of Knee Surgery and, in 2010, achieved a professorship position for "Regenerative Joint Therapy" at the University Hospital, Regensburg. Since 2008 he is also partner at the Sporthopaedicum Regensburg and since 2009 the director of the "FIFA Centre of Excellence for Football Medicine" in Regensburg.

Since 2000, he leads the research at the Department of Trauma Surgery at the University Hospital, Regensburg. For their research, his group was awarded numerous awards such as the Thesis price 1996, Ulm, the Poster Award 1998 of the Austrian Society of Surgery, the Forum price of the German Society for Trauma Surgery in 1999, 2000, 2003, the Günther Schlag Memorial Award in 2002 and the ICRS Poster Award 2010.

His research focus has been the treatment of knee injuries involving the cartilage, meniscus or ligaments. Another major research focus lies in stem cell differentiation for repair of cartilage and meniscus defects and translational research to apply this technology to orthopaedic patients. He published numerous original articles and book chapters in these areas.

Peter has been a member of ESSKA since 2006 and has been active in the ESSKA cartilage committee. He is also a member of AGA (Vice president), DGOOC, DKG, GOTS and ISAKOS.

We welcome Peter to the team of KSSTA Editors. 